\title{
Electrochemical Reduction of Uniformly Dispersed Pt and Ag Nanodots on Carbon Fiber Electrodes
}

\author{
Yi-Hao Pai and Gong-Ru Lin \\ Department of Electrical Engineering, Graduate Institute of Photonics and Optoelectronics, National Taiwan University, \\ 1 Roosevelt Road Section 4, Taipei 10617, Taiwan \\ Correspondence should be addressed to Gong-Ru Lin, grlin@ntu.edu.tw
}

Received 11 May 2009; Accepted 31 August 2009

Recommended by Y. Wang

Electrochemical characterization of the uniformly dispersed Pt and Ag nanodots synthesized after in situ scalable electron-beam reduction on copper grid and carbon-fiber electrode is demonstrated. By employing plasma pretreatment to produce functional organosilicon micronetworks-based reaction sites on copper grid, the size and standard deviation of the electrochemically reduced metallic nanodots can be strictly confined. When detuning the accelerating voltage of electron-beam from 3 to $120 \mathrm{kV}$, the reshaped nanodot diameter enlarges from $12.7 \pm 0.8$ to $18.3 \pm 3.6 \mathrm{~nm}$ due to the gradual self-aggregation. In comparison with sputtering method, the electroactivity of Pt nanodot covered carbon fiber electrode obtained after electron-beam reduction exhibits a larger electroactive surface $\left(\mathrm{S}_{\mathrm{pt}}\right)$ of $16.56 \mathrm{~cm}^{2} / \mathrm{mg}$. The electron-beam reduction provides a better dispersion of the reduced Pt nanodots based catalysts on carbon-fiber electrode, promoting the utilization efficiency of these nanoscale catalyst (defined as the ratio of electroactive to geometric area) from $2.5 \%$ to $7 \%$.

Copyright (C) 2009 Y.-H. Pai and G.-R. Lin. This is an open access article distributed under the Creative Commons Attribution License, which permits unrestricted use, distribution, and reproduction in any medium, provided the original work is properly cited.

\section{Introduction}

At the beginning of the 20th century, Louis de Broglie theorized that the electron had wave-like characteristic with a wavelength far smaller than light visible to the human eye [1]. Soon after in 1932, Knoll and Ruska had produced the first electron microscope (EM), a notable contribution to microstructure studies [1]. The electron microscope is arguably the most efficient instrument for the characterization of materials, as image contrasts and diffraction contrasts can be directly observed. To date, the commercially available EM has been an effective qualitative and quantitative tool for attempting to distinguish among composition and crystalline structure. Noticeably, only a few studies focus on electron-beam effects and the kinetics of the electron-beam process. From previous literature, two different categories of damage can simultaneously result during electron-beam surface irradiation: radiolytic damages, such as contamination, electrostatic charging, and atomic displacement [2]; and direct knock-on collisions of electrons with atomic nuclei, and so forth [3]. The radiolytic damages are easily avoided by establishing an optimal electrical contact or through specimen pretreatment; Stark et al. reported that a precursor of palladium acetate film could reduce electronbeam exposure. They indicated that the band energy of the exposed film had significantly changed during electron-beam exposure [4]. Singh and Marks also studied the kinetics of the electron-beam-induced reduction of tungsten trioxide through a diffusion-controlled process using in situ electron microscopy [5]. As such, the metallic nanodots were reduced by employing an electron-beam; commercially available electron-beam diagnostic instruments, such as scanning electron microscopes, (SEM) or scanning transmission electron microscopes (STEM), are potential candidates for the electron-beam reduction of metallic nanodots. Notably, a few reports have demonstrated that metallic nanodots, through electron-beam-induced reduction, are effective for object application regarding electrodes, catalyst particles, and so forth [6], which ascribe to a strictly controlled nucleation method resulting in the prevention of dot aggregation. Unfortunately, this was an impracticable method for use with a dispersing agent due to the in situ electron-beam 
reaction mechanism being limited. Note that uniformly dispersed metallic nanodots can be prepared using chemical methodology by employing a reducing agent such as sodium borohydride $\left(\mathrm{NaBH}_{4}\right)$ or a dispersing agent such as cetyltrimethylammonium bromide (CTAB) [7-9]. Most of these techniques require strict conditions and tedious procedures for preserving the nanodots' scale for a long time $[8,10]$. Therefore, obtaining metallic nanodots with uniform size distribution on the host matrix through electron-beam reduction is a continuing difficulty. According to literature, the synthesis of excellent functional organosilicon micro networks through spatially confined reaction sites is a viable method which has lately attracted much interest due to the well-defined size distribution [11].

This study employed the plasma technique prior to electron-beam irradiation to create more nucleation sites in order to reach our goal. Following this process, the controlled nucleation of uniformly size-distributed metallic nanodots from the metal-salt precursors under electron irradiation in SEM or STEM was evaluated. The relationship between accelerating voltage and size distribution characteristics of the reduced metallic nanodots is characterized. To better understand the electrode application, the effective active area of the electrode is discussed and compared to other current techniques and processes.

\section{Experimental}

2.1. The Electron-Beam-Induced Reduction Technique. The formation procedure of the electron-beam-induced reduction of metallic nanodots on the host matrix is illustrated in Figure 1(a) which includes plasma surface modification, metal-salt aqueous solutions fabrication and deposition, and electron-beam-induced reduction.

The experimental parameters for optimizing the plasma surface modification and improving the dot-size distribution on the host matrix are listed below. The concentration of the metal-salt aqueous solutions is $0.05 \mathrm{M}$. The homemade carbon film-coated TEM copper grid (see Figure 1(b)) and carbon fiber host matrix treated with argon plasma at $30 \mathrm{~W}, 25$ seconds, were submerged in metal-salt aqueous solutions such as $\mathrm{PtCl}_{4(\text { aq.) }}$ and $\mathrm{AgNO}_{3 \text { (aq.) }}$. To confirm the results of plasma surface modification, the homemade carbon film-coated TEM copper grid and carbon fiber host matrix without plasma treatment were also prepared for comparison. After drying in a vacuum at $28^{\circ} \mathrm{C}$, the carbon film-covered copper grid or carbon fiber samples were placed on a sample holder and inserted into the SEM or STEM. After turning on the accelerating voltage of the EM, the reduction was initiated instantly. The $\mathrm{M}^{\mathrm{n}+}$ ions instantly obtained numerous electrons and immediately reduced to $\mathrm{M}^{0}$ nanodots on the host matrix during e-beam irradiation $[6,12,13]$. To realize the effects of the accelerating voltage, the carbon film-covered copper grid samples were irradiated in a vacuum chamber of $2.0 \times 10^{-6}$ Torr with an accelerating voltage varying from $3 \mathrm{kV}$ to $120 \mathrm{kV}$.

2.2. Fabrication of Pt/Carbon Fiber Electrode. For further applications, tests of the electron-beam-induced reduction technique were also performed on the $\mathrm{Pt} /$ carbon fiber electrode. As such, two sets of electrodes were fabricated, tested, and compared. Details of the electrode fabrication are as follows. First, the carbon fiber was modified with argon plasma to facilitate functional organosilicon micronetwork production. The carbon fiber was then submerged in $0.05 \mathrm{M}$ $\mathrm{PtCl}_{4 \text { (aq.) }}$. After drying in a vacuum chamber, the pretreated carbon fiber was inserted into the EM vacuum chamber. To realize the effective active area of the electrode, another electrode using the sputtering method (PVD, ULVAC VPS020 Quick Coater) was fabricated for comparison.

2.3. Characterization. The fabrication procedure and microstructure analysis of the metallic nanodots were done by using a field emission SEM (JEOL-6700F) and STEM (JEOL-2010). The crystalline phase analysis was performed through comparisons of the selected area diffraction patterns of the electron-beam produced nanodots with those of the standards reported in JCPDS database. The uniformity and dispersion ratio of EM images analysis were estimated by using related software (Digital Micrograph 3.3.1 and Origin R8.0 SRO). X-ray energy-dispersive spectrometer (XEDS, Link ISIS 300) was also employed to characterize the composition. Electroactivities and electrochemical properties of the $\mathrm{Pt} /$ Carbon fiber electrodes prepared between electron-beam and sputtering methods were analyzed by cyclic voltammetry (CV) through the CHI614B electrochemical analyzer.

\section{Results and Discussion}

3.1. Electron-Beam-Induced Metallic Nanodots. To realize the effects of plasma surface modification, the solid mask was employed to shelter a half-copper grid from plasma treatment. Again, this study utilized the previous method to obtain the reduced metallic nanodots. Using the electronbeam reduction of Pt nanodots as an example, the reactions in the metal-salt aqueous solution and the EM chamber are described in Figure 2.

During electron-beam irradiation with SEM or STEM, the monodispersed metallic nanodots are in situ and locally synthesized without using any reducing agents. When electron-beam-induced Pt reduction is performed with a pretreated copper grid using the plasma technique, it exhibits a highly concentrated nanodot distribution with a dot density of $8.42 \times 10^{9} \mathrm{~cm}^{-2}$. The density decreases to $1.56 \times$ $10^{8} \mathrm{~cm}^{-2}$ with density approaching two orders of magnitude under the accelerating voltage of $80 \mathrm{kV}$. In addition, this increases the standard deviation of size compared to the electron-beam induced Pt nanodot reduction without plasma modification. As such, the plasma surface modification causes a narrowing in size and standard deviation, which is attributed to the spatially confined reaction sites of smallsize Pt nanodots [11].

Note that (I) and (II) in Figure 2(b) express possible reactions in the current study. (I) in Figure 2(b) describes decomposition of the tiny $\mathrm{PtCl}_{4}$ dot or film during the ebeam irradiation. It should be noted that the partial $\mathrm{PtCl}_{4}$ likely precipitates on the host matrix in the vacuum chamber. Nevertheless, due to the melting effect of smaller sized grains 


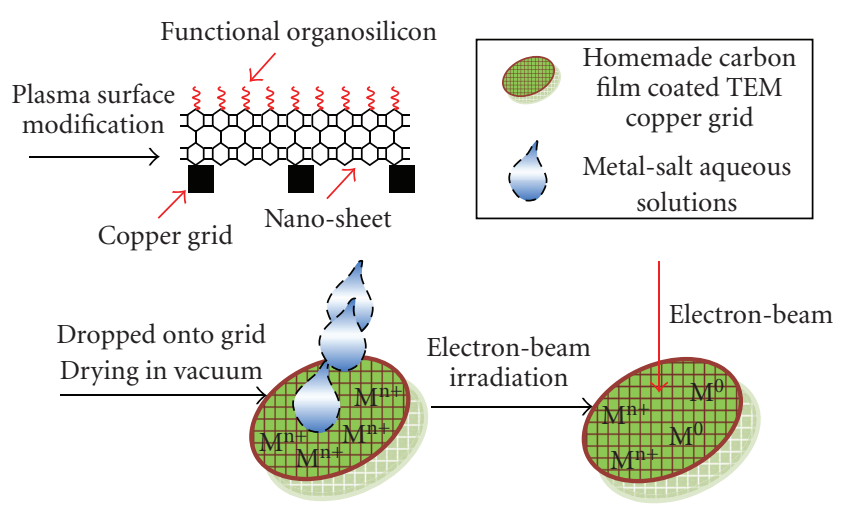

(a)

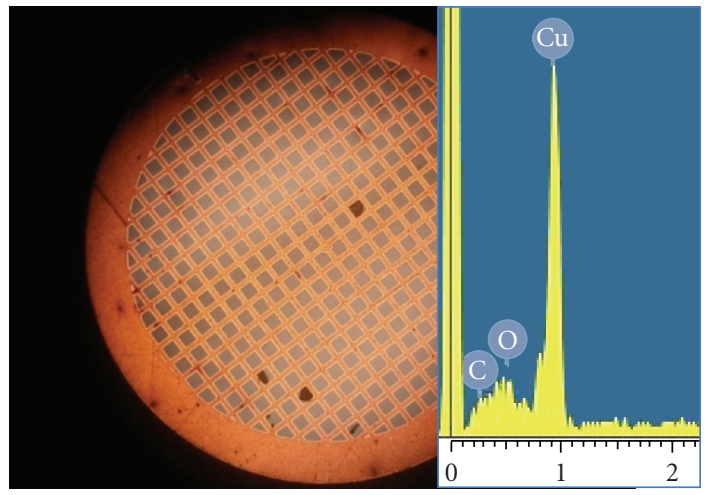

(b)

FIgURE 1: (a) Schematic illustration of the electron-beam-induced reduction for electrode fabrication, and (b) OM image and XEDS spectrum of the homemade carbon film-coated TEM copper grid.

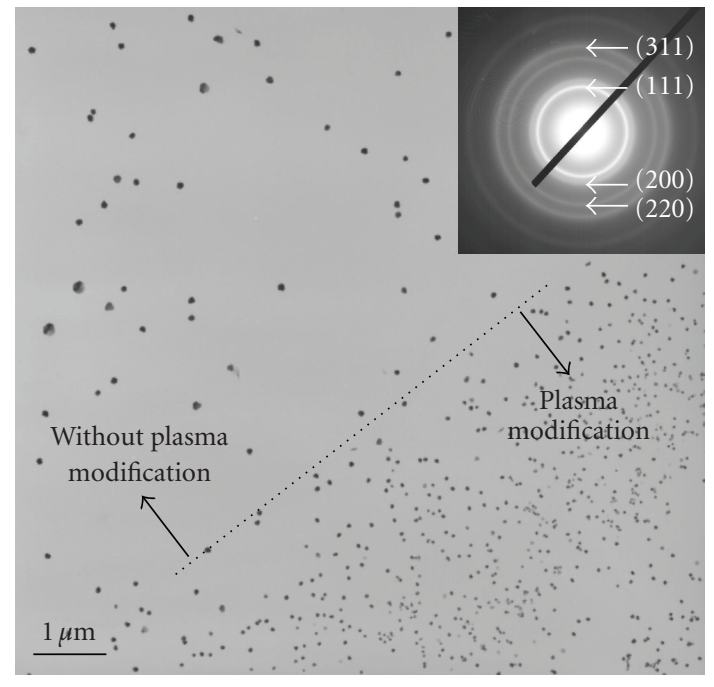

(a)

\begin{tabular}{|c|c|c|}
\hline \multicolumn{3}{|c|}{ Dissolution of metallic salt precursor: } \\
\hline \multicolumn{3}{|c|}{ (I) $\quad \mathrm{PtCl}_{4(\mathrm{~s})} \longrightarrow \mathrm{Pt}_{(\mathrm{aq})}^{4+}+4 \mathrm{Cl}_{(\mathrm{aq})}^{-}$} \\
\hline \multicolumn{3}{|c|}{ Electron-beam reduction of Pt nanodots: } \\
\hline \multicolumn{3}{|c|}{$2 \mathrm{PtCl}_{4(\mathrm{~s})} \underset{\Delta}{\longrightarrow} 2 \mathrm{Pt}_{(\mathrm{s})}+4 \mathrm{Cl}_{(2 \mathrm{~g})}$ or } \\
\hline \multicolumn{3}{|c|}{ (II) $\mathrm{Pt}_{(\mathrm{aq})}^{++}+4 e^{-} \longrightarrow \mathrm{Pt}_{(\mathrm{s})}$} \\
\hline \multirow{2}{*}{$\begin{array}{l}\text { Without plasma } \\
\text { modification }\end{array}$} & Size $(\mathrm{nm})$ & Density $\left(\mathrm{cm}^{-2}\right)$ \\
\hline & $117 \pm 14$ & $1.56 \times 10^{8}$ \\
\hline \multirow{2}{*}{$\begin{array}{l}\text { With plasma } \\
\text { modification }\end{array}$} & Size $(\mathrm{nm})$ & Density $\left(\mathrm{cm}^{-2}\right)$ \\
\hline & $48 \pm 3$ & $8.42 \times 10^{9}$ \\
\hline
\end{tabular}

(b)

FIGURE 2: (a) The STEM bright-field image; (b) the reaction mechanism and summarized of Pt nanodots demonstrated by e-beam reduction with and without plasma modification.

$[14,15]$, the melting point is quite low compared to that of the bulkier grains with regard to the decomposition of tiny $\mathrm{PtCl}_{4}$ dots or films through electron-beam irradiation. (II) in Figure 2(b) concerns the discriminated adsorption. The surface functional organosilicon micronetwork on the copper grid easily absorbs the metallic ions [16], which can promote metallic nanodot reduction on the host matrix. Furthermore, none of the Pt oxide- $\left(\mathrm{PtO}_{2-}\right)$ related SAD signals are identified; this indicates that the electron-beam reduced Pt nanodot has not been oxided at the beginning.

To realize the effect of accelerating voltages on $\mathrm{Pt}$ nanodot size and distribution characteristics during reduction, the in situ TEM results of $\mathrm{Pt}$ nanodots are compared with accelerating voltages varying from $3 \mathrm{kV}$ to $120 \mathrm{kV}$, as shown in Figure 3. According to the statistical analysis [17], to quantify the relationships among accelerating voltages and size distribution characteristics, the coefficients of size deviation $\left(\sigma_{D} / \bar{D}\right)$ and displacement deviation $\left(\sigma_{X} / \bar{X}\right)$ for the self-aggregated $\mathrm{Pt}$ nanodots are defined by

$$
\begin{aligned}
& \frac{\sigma_{D}}{\bar{D}}=\frac{\left(1 /(n-1) \sum_{i=1}^{n}\left(D_{i}-\bar{D}\right)^{2}\right)^{0.5}}{\bar{D}} \times 100 \%, \\
& \frac{\sigma_{X}}{\bar{X}}=\frac{\left(1 /(n-1) \sum_{i=1}^{n}\left(X_{i}-\bar{X}\right)^{2}\right)^{0.5}}{\bar{X}} \times 100 \%,
\end{aligned}
$$

where the $\sigma_{D}$ and $\sigma_{X}$ are the size standard deviation and displacement, the $D_{i}$ and $\bar{D}$ are the diameter of each $\mathrm{Pt}$ nanodot and the average number, and $X_{i}$ and $\bar{X}$ denote the displacement between $\mathrm{Pt}$ nanodots, respectively. Note that the $\sigma_{D} / \bar{D}$ must remain small to keep similarly sized nanodot, whereas the $\sigma_{X} / \bar{X}$ should be as large as possible to obtain uniform distribution on the host matrix. 


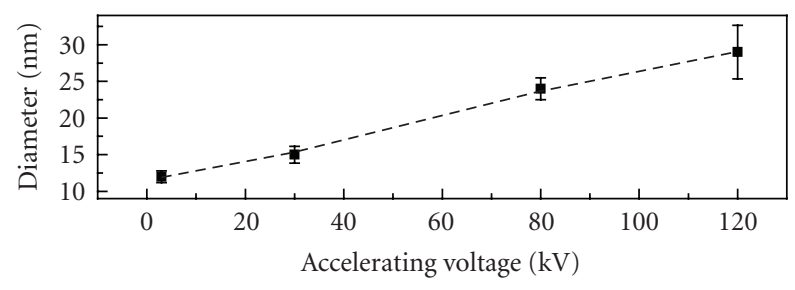

(a)

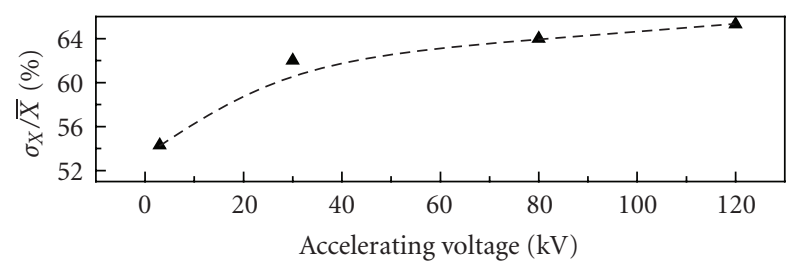

(b)

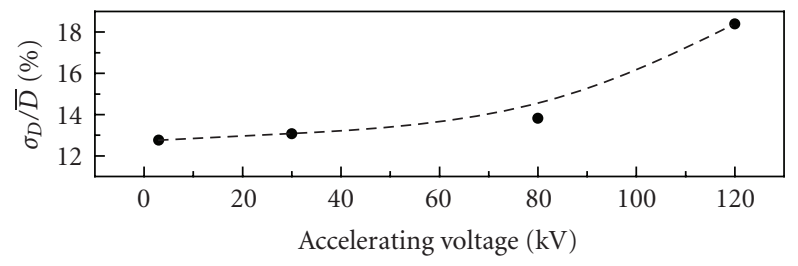

(c)

Figure 3: The accelerating voltage dependent the diameter, $\sigma_{D} / \bar{D}$, and $\sigma_{X} / \bar{X}$ of Pt nanodot.

The $\mathrm{Pt}$ nanodots prepared with an accelerating voltage of $3 \mathrm{kV}$ reveals a small size with diameter of $12 \pm 0.8 \mathrm{~nm}$ corresponding to the distribution characteristic with $\sigma_{D} / \bar{D}$ of $12.76 \%$ and $\sigma_{X} / \bar{X}$ of $54.3 \%$, respectively. However, the size and standard deviation of Pt nanodots are concurrently enlarged by enhancing the accelerating voltage from $3 \mathrm{kV}$ to $120 \mathrm{kV}$, which is attributed to both the damage effect and crystalline regrowth occurring at high-accelerating voltage irradiation $[1,18]$.

To further extend the electron-beam reduction technique to other metal-salt aqueous solutions, such as $\mathrm{AgNO}_{3}$, and other host matrices, including Formvar thin polymer film and Si nanopillar, the STEM micrograph of the Formvar thin polymer film and Si nanopillar after submersion in the $\mathrm{AgNO}_{3}$ aqueous solution of $0.05 \mathrm{M}$ and drying in a vacuum are illustrated in Figure 4 . Under $80 \mathrm{kV}$ electronbeam irradiation, the bright field image reveals the synthesis of $\mathrm{Ag} /$ the Formvar thin polymer film and $\mathrm{Ag} / \mathrm{Si}$ nano-pillar with diameters of $12 \pm 1.5 \mathrm{~nm}$ and $8 \pm 1.2 \mathrm{~nm}$, respectively.

Furthermore, both SAD analyses of the grown Ag nanodots are identified to be polycrystalline face-centered cubic (FCC) structures. Among all oriented growth at (111), (200), and (220) for the electron-beam-reduced Ag nanodots, the main growths are (111) directional with corresponding lattice spacing of $d=2.35 \AA$, respectively. In line with previous results in literature [19], it is found that the growthorientation of the present work is the same as other methods, such as chemical reduction.
3.2. Electroactivity of Pt/Carbon Fiber Electrodes. To obtain information concerning the electrode activities, electrochemical analysis and cyclic voltammograms were performed for the Pt/carbon fiber electrodes fabricated from electron-beam reduction and sputtering methods, respectively, and are illustrated in Figure 5. This indicates that the Pt/carbon fiber electrode fabricated using the electronbeam reduction method has a higher specific current in the hydrogen region than that of the electrode with sputtered Pt nanodots [20]. This is due to the high dispersion of the Pt catalysts. To confirm the above results, the SEM was employed to observe the $\mathrm{Pt} /$ carbon fiber electrodes fabricated with both electron-beam reduction and sputtering methods, as shown in Figure 5 (inset (a) and (b)).

This suggests that the $\mathrm{Pt}$ catalysts were not as well dispersed or mutually aggregated on the top surface as that of the electrode with electron-beam-induced $\mathrm{Pt}$ nanodot reduction. Note that the distribution of the $\mathrm{Pt}$ catalysts shown above is favorable since much more of the electrode space within the carbon fiber was occupied. To quantify the results, the electroactivity of the $\mathrm{Pt} /$ carbon fiber electrode was calculated by integrating the hydrogen adsorption and desorption curves on the CV diagram [20,21]. The active surface area $S_{\mathrm{Pt}}$ for the electrodes is obtained from $S_{\mathrm{Pt}}=$ $Q_{\mathrm{H}} / Q_{\mathrm{H}}^{0}$, which calculates the charge transferred for hydrogen adsorption $Q_{\mathrm{H}}$ where $Q_{\mathrm{H}}^{0}$ is the charge per $\mathrm{cm}^{2}$ of Pt with a monolayer Hydrogen adsorption of $210 \mu \mathrm{C} / \mathrm{cm}^{2}$ [20]. The calculated $S_{\mathrm{Pt}}$ for two electrodes was $16.56 \mathrm{~cm}^{2} / \mathrm{mg}$ and $4.14 \mathrm{~cm}^{2} / \mathrm{mg}$, respectively. In addition, the geometrical specific surface areas $\left(S_{\text {geo }}\right)$ of Pt catalysts can further be calculated from $S_{\text {geo }}=0.284 / d[21]$, where $d$ is the diameter of the Pt catalysts. In contrast with $S_{\text {act }} / S_{\text {geo }}$, it indicates that the Pt catalysts fabricated with the electron-beam have surface atoms of $6.98 \%$ contributing to the electrochemical reactions, which is higher than that of the electrode fabricated using the sputtering method with $S_{\text {act }} / S_{\text {geo }}$ of $2.34 \%$. It should be noted that the Pt catalysts fabricated using the two methods were different sizes, which may play an important role in affecting the catalytic utilization. In conclusion, the above results provide quantitative evidence that the electron-beam-reduced $\mathrm{Pt}$ nanodots have a larger electroactive surface, which implies that the electron-beam method has a better distribution than other methods in relation to the whole electrode space [20]; this is seen qualitatively in Figure 5.

\section{Conclusions}

Electron-beam-induced reduction has emerged as a novel technology to rapidly prepare metallic nanodots. During electron-beam irradiation within SEM or STEM, the metallic nanodots are in situ and locally synthesized. It exhibits a highly concentrated nanodot distribution with density of $8.42 \times 10^{9} \mathrm{~cm}^{-2}$ by employing plasma pretreatment to produce functional organosilicon micronetworks-based reaction sites on copper grid, whereas the density decreases to $1.56 \times 10^{8} \mathrm{~cm}^{-2}$ under the accelerating voltage of $80 \mathrm{kV}$. By changing the accelerating voltage from 3 to $120 \mathrm{kV}$, it reveals that the size enlarges with diameter varied from $12.7 \pm 0.8$ 


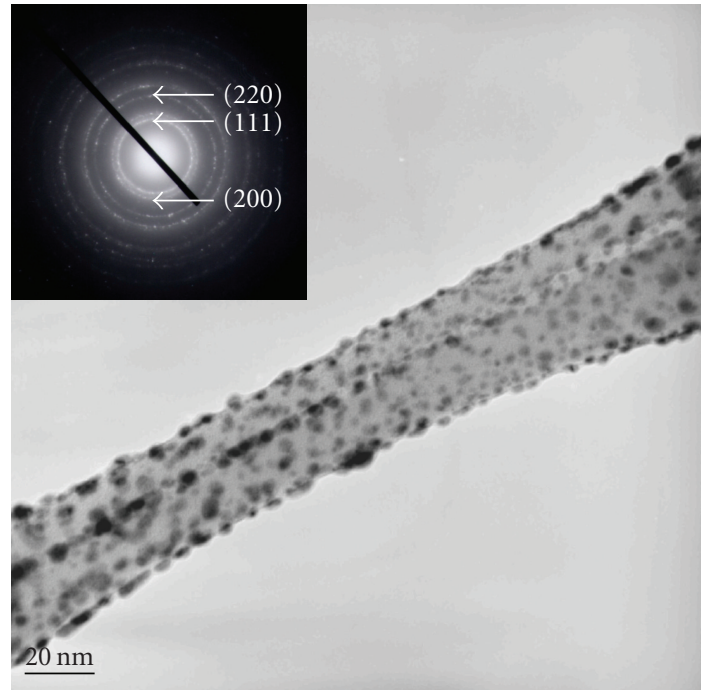

(a)

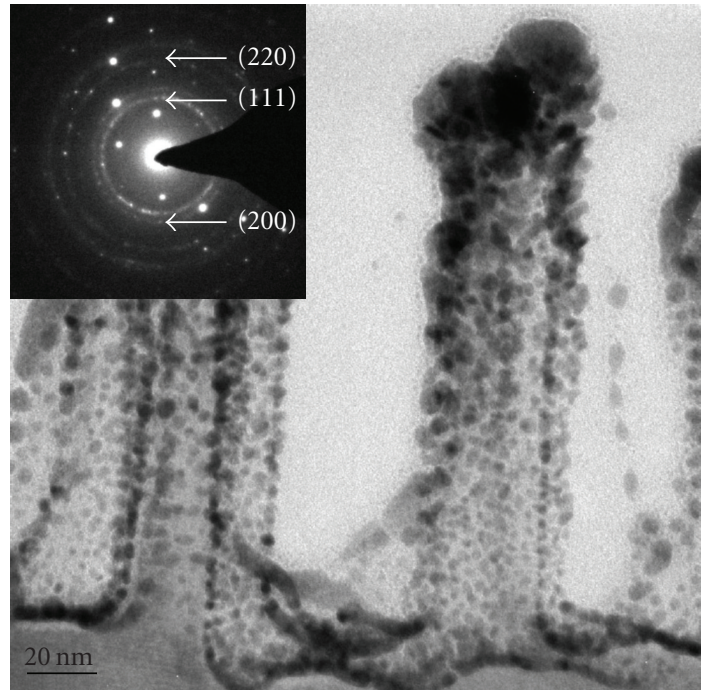

(b)

Figure 4: The STEM bright field image of (a) Ag/the Formvar thin polymer film and (b) Ag/Si nanopillar demonstrated by e-beam reduction. (Inset) the $\mathrm{SAD}$ analysis of the grown Ag nanodots.

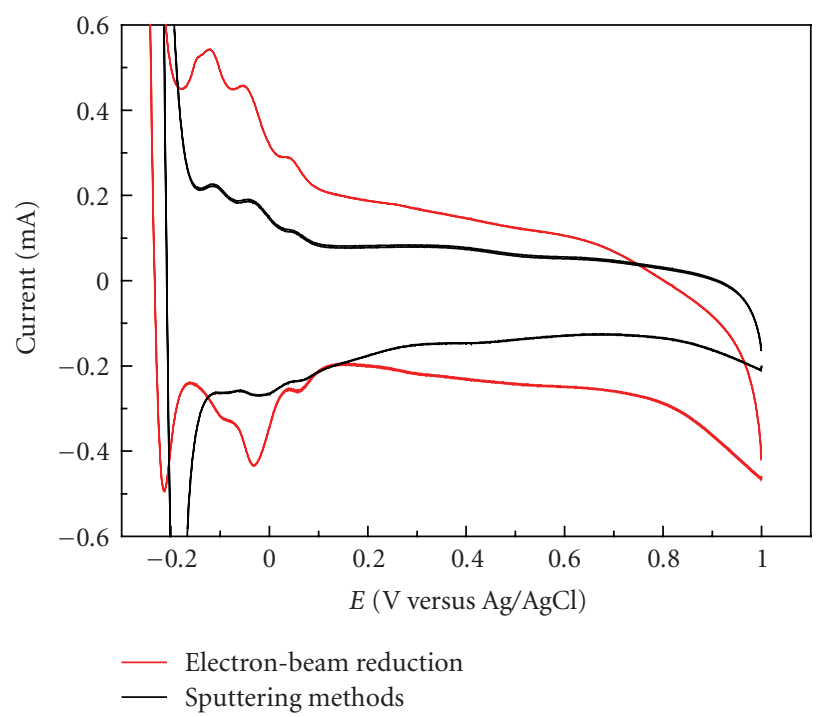

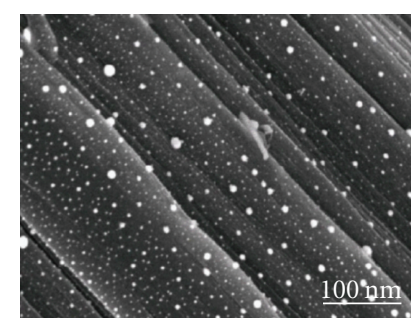

(a)

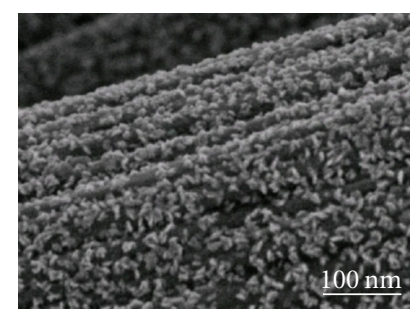

(b)

Figure 5: Cyclic voltammograms (in $1 \mathrm{M} \mathrm{H}_{2} \mathrm{SO}_{4}$ solution) of $\mathrm{Pt} / \mathrm{C}$ electrodes fabricated from electron-beam reduction and sputtering method; (Inset: SEM micrograph of Pt/C electrodes fabricated from (a) electron-beam reduction and (b) sputtering methods).

to $18.3 \pm 3.6 \mathrm{~nm}$, respectively, due to the damage effect and gradual self-aggregation occurred at high-accelerating voltage irradiation. Furthermore, the electroactivity of Pt/carbon fiber electrode fabricated between electron-beam reduction and sputtering indicates that the electron-beam-reduced $\mathrm{Pt}$ nanodots have a larger electroactive surface with $S_{\mathrm{pt}}$ of $16.56 \mathrm{~cm}^{2} / \mathrm{mg}$, which imply that the electron-beam method has a better distribution than another method in the whole electrode space. The impact of this work is greatly simplifying the tedious procedure for metallic nanodot synthesis without using any reducing agents, thus enhancing a relatively good dispersion ratio of metallic nanodots to promote electroactivity of electrode.

\section{Acknowledgments}

This work was supported in part by the National Science Council (NSC) of China and Aim for Top University Project, under Grants NSC 98-2218-E-002-022 and 97R0044, respectively.

\section{References}

[1] D. B. Williams and C. B. Carter, Transmission Electron Microscopy, Plenum, New York, NY, USA, 1996.

[2] R. F. Egerton, P. Li, and M. Malac, "Radiation damage in the TEM and SEM,” Micron, vol. 35, no. 6, pp. 399-409, 2004. 
[3] V. H. Crespi, N. G. Chopra, M. L. Cohen, A. Zettl, and S. G. Louie, "Anisotropic electron-beam damage and the collapse of carbon nanotubes," Physical Review B, vol. 54, no. 8, pp. 59275931, 1996.

[4] T. J. Stark, T. M. Mayer, D. P. Griffis, and P. E. Russell, "Electron beam induced metallization of palladium acetate," The Journal of Vacuum Science and Technology B, vol. 9, no. 6, pp. 34753478, 1991.

[5] S. R. Singh and L. D. Marks, "Diffusion during electronbeam-induced reduction of tungsten trioxide," Philosophical Magazine Letters, vol. 60, no. 1, pp. 31-36, 1989.

[6] Y.-H. Pai, H.-F. Huang, Y.-C. Chang, C.-C. Chou, and F.S. Shieu, "Electron-beam reduction method for preparing electrocatalytic particles for membrane electrode assemblies (MEA)," Journal of Power Sources, vol. 159, no. 2, pp. 878-884, 2006.

[7] E. Keçeli and S. Özkar, "Ruthenium(III) acetylacetonate: a homogeneous catalyst in the hydrolysis of sodium borohydride," Journal of Molecular Catalysis A, vol. 286, no. 1-2, pp. 87-91, 2008.

[8] B. Yin, H. Ma, S. Wang, and S. Chen, "Electrochemical synthesis of silver nanoparticles under protection of poly $(\mathrm{N}$ vinylpyrrolidone)," Journal of Physical Chemistry B, vol. 107, no. 34, pp. 8898-8904, 2003.

[9] S. Liu, J. Yu, X. Zhao, and B. Cheng, "Effects of polyvinylpyrrolidone and cetyltrimethylammonium bromide on morphology of lead tungstate particles," Journal of Alloys and Compounds, vol. 433, no. 1-2, pp. 73-78, 2007.

[10] R. M. Penner, "Mesoscopic metal particles and wires by electrodeposition," Journal of Physical Chemistry B, vol. 106, no. 13, pp. 3339-3353, 2002.

[11] F. Baumann, B. Deubzer, M. Geck, J. Dauth, S. Sheiko, and M. Schmidt, "Soluble organosilicon micronetworks with spatially confined reaction sites," Advanced Materials, vol. 9, no. 12, pp. 955-958, 1997.

[12] M. F. Abou Taleb, G. A. Mahmoud, S. M. Elsigeny, and E.-S. A. Hegazy, "Adsorption and desorption of phosphate and nitrate ions using quaternary (polypropylene-g-N,N-dimethylamino ethylmethacrylate) graft copolymer," Journal of Hazardous Materials, vol. 159, no. 2-3, pp. 372-379, 2008.

[13] R. Wahl, M. Mertig, J. Raff, S. Selenska-Pobell, and W. Pompe, "Electron-beam induced formation of highly ordered palladium and platinum nanoparticle arrays on the S layer of Bacillus sphaericus NCTC 9602," Advanced Materials, vol. 13, no. 10, pp. 736-740, 2001.

[14] J.-G. Zhu, Y. Zheng, and G. A. Prinz, "Ultrahigh density vertical magnetoresistive random access memory (invited)," Journal of Applied Physics, vol. 87, no. 9, pp. 6668-6673, 2000.

[15] W. Rabaud, L. Saminadayar, D. Mailly, K. Hasselbach, A. Benoit, and B. Etienne, "Persistent currents in mesoscopic connected rings," Physical Review Letters, vol. 86, no. 14, pp. 3124-3127, 2001.

[16] H. Wei, J. Li, Y. Wang, and E. Wang, "Silver nanoparticles coated with adenine: preparation, self-assembly and application in surface-enhanced Raman scattering," Nanotechnology, vol. 18, no. 17, Article ID 175610, 5 pages, 2007.

[17] C. M. Douglas and C. R. George, Applied Statistics and Probability for Engineers, John Wiley \& Sons, New York, NY, USA, 4th edition, 2007.

[18] P. Kern, Y. Müller, J. Patscheider, and J. Michler, "Electronbeam-induced topographical, chemical, and structural patterning of amorphous titanium oxide films," Journal of Physical Chemistry B, vol. 110, no. 47, pp. 23660-23668, 2006.
[19] D. K. Božanić, V. Djoković, J. Blanuša, P. S. Nair, M. K. Georges, and T. Radhakrishnan, "Preparation and properties of nano-sized Ag and Ag2S particles in biopolymer matrix," European Physical Journal E, vol. 22, no. 1, pp. 51-59, 2007.

[20] Y.-H. Pai, H.-F. Huang, Y.-C. Chang, C.-C. Chou, and F.S. Shieu, "Electron-beam reduction method for preparing electrocatalytic particles for membrane electrode assemblies (MEA)," Journal of Power Sources, vol. 159, no. 2, pp. 878-884, 2006.

[21] Y. Xing, "Synthesis and electrochemical characterization of uniformly-dispersed high loading $\mathrm{Pt}$ nanoparticles on sonochemically-treated carbon nanotubes," Journal of Physical Chemistry B, vol. 108, no. 50, pp. 19255-19259, 2004. 

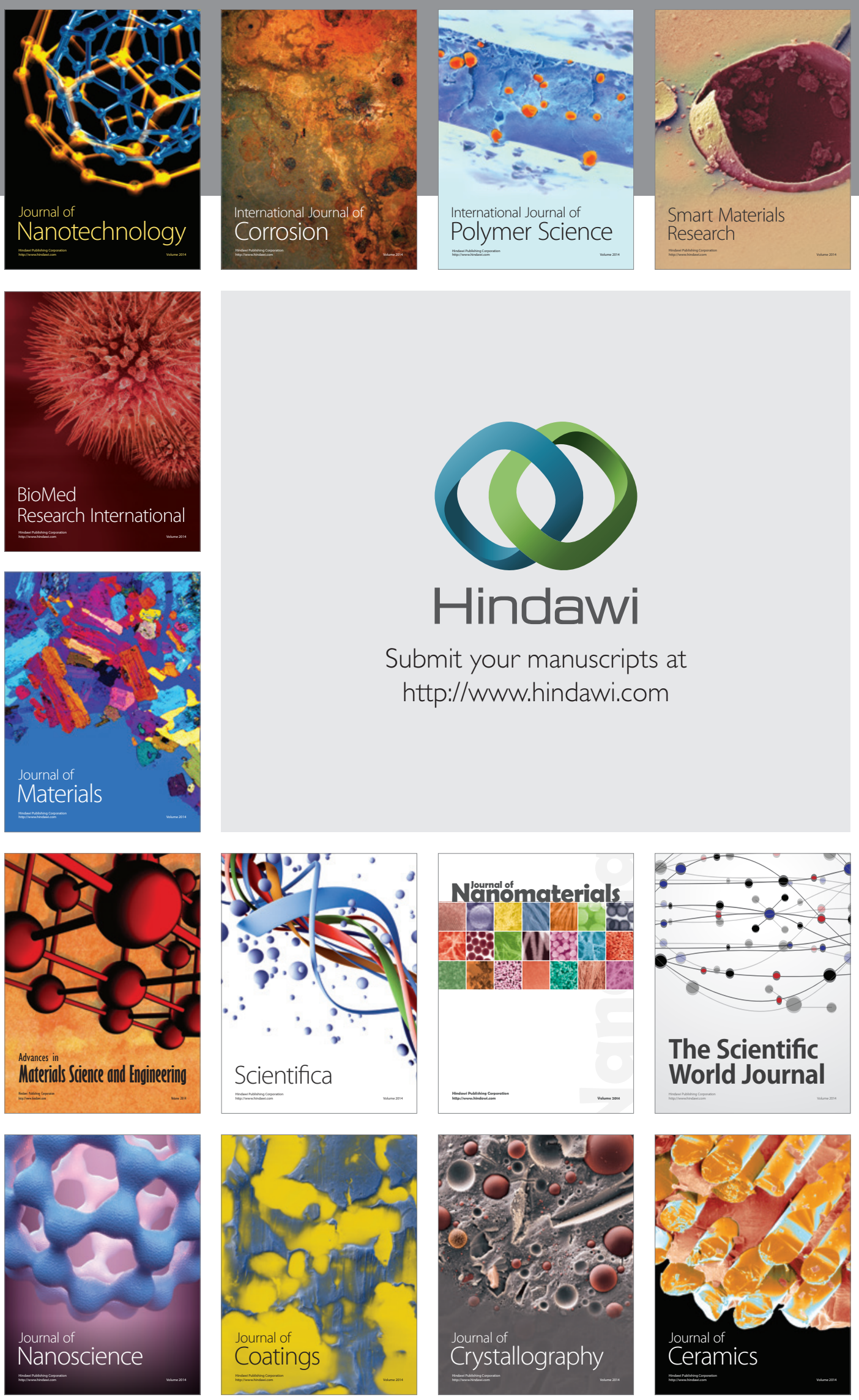

The Scientific World Journal

Submit your manuscripts at

http://www.hindawi.com

\section{World Journal}

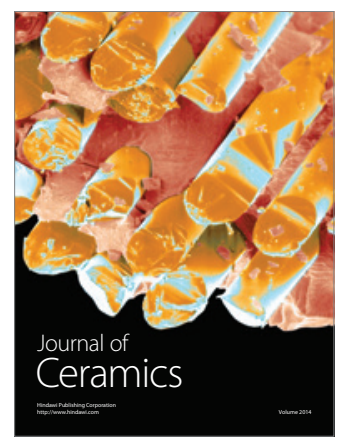

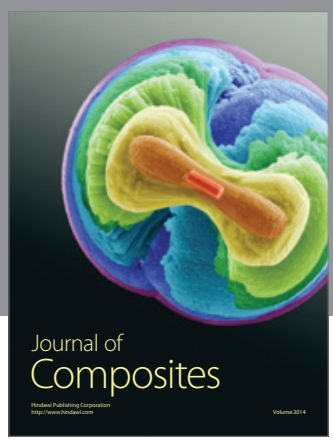
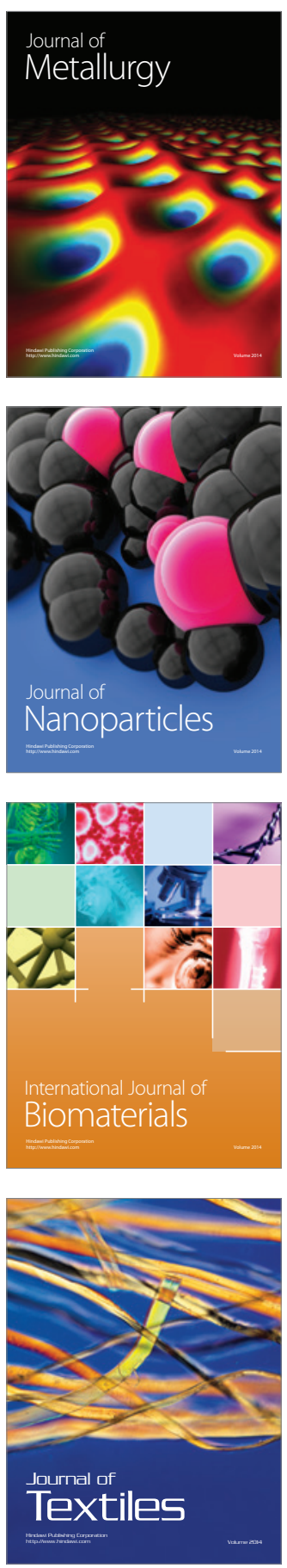